\title{
Human Resource Management Practices and Organizational Commitment in Yemen Islamic Banking Sector: The Mediating Role of Tribalism
}

\author{
Ali Salman Emam ${ }^{1 *}$, Juraifa Bte Jais ${ }^{2}$ \\ * College of Business Administration, University of Hafr Al-Batin, Hafr Al Batin, Saudi Arabia. \\ ${ }^{2}$ Lecturer in the Department of Management \& HRM Universiti Tenaga Nasional, Malaysia.
}

\author{
Article Info \\ Article history: \\ Received 12 December 2019 \\ Received in revised form 10 January 2020 \\ Accepted 27 February 2020 \\ Published 01 April 2020
}

\begin{abstract}
This paper endeavors to propose a conceptual framework to determine the relationship between HRM practices and organizational commitment through the Tribalism Relations as a mediating variable in Yemen Islamic banks sector. Indeed, the rationale for introducing HRM practices is to increase employee commitment to ensure positive outcomes. The search for the answer to this question focuses on management's orientation of employees, departmental guidelines and career development practices, and their relationship to employees' level of commitment, using a random sample of Islamic bank employees. The study results show that there is a strong relationship between human resource management practices and organizational commitment in theory, as theoretical concepts of the mediator's effect on the relationship clarify, particularly within Yemen Tribal society.
\end{abstract}

Keywords: HRM practices, Organizational Commitment, Tribalism, Yemen Islamic Banks Sector

\section{Introduction}

Organizational commitment has received more attention in organizational research and practice because of its positive outcomes. Much research has been done to examine the antecedents of commitment to finding the most significant factors determining OC. Earlier studies suggested that there are many OC antecedents, such as work experiences, personal and organizational factors, and human-resource practices. Most literature, however, focused on developed countries. In contrast, others have examined the effect of the practices of human-resource practices on OC among the emerging nations (Aladwan et al., 2015; Alkadash, 2020). Indeed, third-world countries have a unique context that differs from the developed countries' context. Thus, there is a call for research to revitalize HRM practices in all cultural contexts. In line with the discussion, Arabic countries possess unique social and cultural values that hugely affect managerial functions. Altarawneh (2009) reported that the behaviors of individual and administrative practices in Arabic countries are affected significantly by these countries' cultures. In the previous studies, the culture was found as an essential mediator between the various stakeholders (Yamao \& Sekiguchi, 2015).

Tribalism remains a major cultural factor in many Arab countries, particularly in Yemen. Tribalism in Yemen is responsible for underdevelopment and corruption, serving as a significant obstacle that stands in the way of democracy and socio-economic development (Baabbad, 2015). It is argued that with the presence of Tribalism, the commitment and loyalty to the tribe will be higher than the commitment and dedication to the country or organization (Brandt, 2017). Therefore, it is expected that this study will contribute to enriching the existing literature by investigating the culture's powerful effect on Tribalism on the HRM and OC relationship in developing contexts such as Yemen. Therefore, importing Western HRM practices to third-world countries like Arab countries by neglecting the differences in the cultural context could be unreasonable; there is a gap in the previous literature in terms of examining the effect of human resource practices on commitment where inconsistent results existed. Another gap that can be extracted from the literature is factors, which might strengthen or weaken the relationship between HR practices and OC. However, it was found that the impact of Tribalism as unique characteristics in the Yemeni context is not yet examined. Yemen is considered the poorest country in the Arab region and has intense Tribalism.

Therefore, this study assesses the mediating impact of Tribalism on the relationship between HRM and organizational commitment among Islamic banks. This study's focus is on the banking sector, which is considered a leading driver of economic growth and development by academics and practitioners. 


\section{Literature Review}

\subsection{HRM Practices}

HRM practices are the policies and practices obligatory for managing the human resource in an organization to achieve organizational goals. They defined HRM practices as the activities of managing the human capital in the organization which is directly connected to the managerial functions such as planning for Recruitment and Selection, Training and Development, Incentive System and Performance Appraisal, utilizing and maximizing the capabilities and potential of employees in the organization (DeCenzo et al., 2016). HRM practices also determine employees' progress and performance by influencing staff in the organization positively or negatively (Hassan \& Mahmood, 2016). The excellent quality HRM practices enhance the organization's internal capacity and social relations, continuity, and motivation in the organization to build long-term commitment. The study identifies four HRM practice areas (Recruitment and Selection, Training and Development, Incentive System, and Performance Appraisal) that might impact organizational commitment in Yemen the Islamic banking sector.

\subsection{Organizational Commitments}

Organizational Commitment (OC) is a complex phenomenon. OC has been developed in the organization's literature; OC can be understood as a pattern of behavior and motivating force. Aladwan et al. (2015) stated that OC is widely described as a critical factor in building organizational relationships between individuals and organizations. Yamao \& Sekiguchi (2015) indicated that OC could be defined as the relative strength of the individual related to the achievement of the organization's goals. Zaitouni et al. (2011) stressed that two models dominate OC's concept and measurement: The first model, Mowday, Porter, and Steers model (1974). The attitudinal model initiated by (Steers \& Porter, 1974) is the most famous in conceptualizing OC. A decade later. Palmer (2000) adds that researchers have criticized this model because the concept is general and lacks precision. The second model Allen and Meyer's model emerge strongly as a destination alternate to Mowday and others, model it was proposed both as an alternative definition and measurement, according to this viewpoint, OC is the feeling of obligation to stay with the organization: feelings resulting from the internalization of normative pressures exerted on an individual before entry or following entry, this conceptualization of has become a widely accepted theoretical framework for several research studies. This model identifies three different OC components: Affective Commitment, Continuance Commitment, Normative Commitment (Aladwan et al., 2015).

\subsection{Tribalism in Yemen}

According to Brandt (2017), some studies suggest that the tribes constitute about $85 \%$ of Yemen's population; the tribe is the basic social unit and structural. In general, the tribe is also considered the basic social unit in the Arabian Peninsula. Tribalism in Yemen has social and political significance since it constitutes the main point of customs and traditions for most Yemeni people. A Yemeni tribe is a corporate unit that has maintained its significant social and cultural responsibility. Tribalism in Yemen gives protection assurance to members of the tribe; therefore, tribesmen protect and help each other when there is a need to do so. Rights and benefits from Tribalism membership are enjoyed by the Tribesmen, who in turn have responsibilities to perform (Adra, 2016).

\subsection{HRM practices and Organizational Commitment}

Many studies have shown HRM practices had a significant positive relationship with OC. For example, Lamba \& Choudhary (2013) revealed that HRM practices provide an edge to employee commitment towards an organization's goal in the global competitive market in India's various sectors. Similarly, research on Chinese private-owned IT enterprises indicated four dimensions: information sharing, training and development, Recruitment and Selection, and compensation management, which had a positive effect on IT employees' OC (Qiao et al., 2008; Alkadash, 2017). While Chew \& Chan (2008) also showed that OC was positively affected by HRM practices in nine Australian organizations. In addition to that, some studies found the mediating effect of relations between HRM and OC. For example, (Zaitouni et al., 2011) found cultural factors and social dimensions as different customs and traditions in Kuwait's banking sector influence the impact of HRM on CO. Yamao \& Sekiguchi (2015) found language is one of the important cultural factors in Japan. HRM practices that promote learning a foreign language have direct and interactive effects on the affective and normative commitment to their firms' globalization through HRM practices. Aladwan et al. (2015) and Yamao \& Sekiguchi (2015) examined the effects of HRM practices on OC in the Middle Eastern context. Their findings indicated that the causal model is consistent with the data and contributes to a fuller understanding of the association between HRM practices and OC. Based on the above discussion, the following hypothesis is developed:

- H1: There is a significant relationship between Human Resources Management practices and organizational commitment to employees in the Yemen Islamic banking sector. 


\subsection{Recruitment \& Selection \& Organizational Commitment}

According to Warsame (2015), extensive recruitment and selection of the best might increase affective commitment, maintaining that the practices help ensure that only people who are a good fit with an organization's goal and culture are separated. According to Katou (2008), there is an urgent necessity for recruiting candidates who are committed to organizational goals and values. Due to diversity in the business environment and complex job insecurity, retaining workers is a cheaper and better option than hiring new ones. An organization should treat its employees as partners. This would help motivate them to achieve their goals creatively, helping the organization face global challenges with confidence and competitive action (Azim et al., 2019). Palmer (2000) showed that OC dimensions are related to strategic human resource management as. Recruitment and selection enhance employee commitment and personal efficiency. Thus, the following hypothesis is predicted:

- H1a: There is a significant relationship between Recruitment and Selection and Organizational Commitment to employees in the Yemen Islamic banking sector.

\subsection{Training and development and Organizational Commitment}

Training and developing employees are increasingly recognized as an essential aspect of best HRM practices. Previous empirical studies have provided extensive evidence that training and development facilitate skills updating, increased commitment, well-being, and a sense of belonging, directly strengthening its competitiveness. Emam et al. (2019) assured that training and development are closely associated with work values, performance, and OC. A research was conducted in Turkey; the results revealed that all training dimensions positively affected employee commitment (Emam et al., 2019). Accordantly, McGuire et al. (2010) found the association between employees' perceptions of diversity of training existence and OC and career satisfaction effectiveness. The survey included nine large organizations in corporate Canada. The paper shows that employees who perceived diversity training to be effective were significantly more committed to their organizations and more satisfied with their careers than employees who viewed diversity training to be ineffective or nonexistent. Another study was conducted in the Western part of China on training and development showed that training is positively related to OC and employability (Wang et al., 2020). According to the above discussion, the following hypothesis is proposed:

- H1b: There is a significant relationship between training and development and Organizational Commitment to employees in the Yemen Islamic banking sector.

\subsection{Incentives System and Organizational Commitment}

The reward system is essential as incentives for committed and motivated employees to achieve organizational goals. Incentives system for quality efforts appears to have a significantly positive relation to employee morale (Eunice, 2014). Similarly, Zaitouni et al. (2011) found a positive impact on profit sharing on OC. Based on hygiene/motivator theory, recognition is one of the four motivators, which can contribute to secure employees' commitment to their jobs and make their jobs more enjoyable. Zaitouni et al. (2011) revealed a definite link between incentives packages and employee commitment. When employees design their incentive and incentive plans, they derive a greater sense of job satisfaction and control over their work, resulting in more substantial commitment. Better work values, recognition, and remuneration, which are given to employees, will also affect their willingness to stay in the organization because a properly developed and managed incentives system can be a vehicle for high performance, work satisfaction, and OC. For example, many organizations have adopted flexible incentives approaches because they believe that people value the ability to choose the incentives process that matches their values and maximizes personal satisfaction (Hsieh et al., 2018). Thus, the following hypothesis is developed:

- H1c: There is a significant relationship between the Incentives system and Organizational Commitment to employees in the Yemen Islamic banking sector.

\subsection{Performance Appraisal and Organizational Commitment}

Hassan \& Mahmood (2016) argued that performance appraisal is a fundamental HRM function, effective performance appraisals as essential factors, training effectiveness, staffing, and incentive system effectiveness. Nevertheless, it maintained that its usefulness in managerial decisions partly depends on the accuracy of the information it provides. The performance appraisal system is defined as a planned and organized process that evaluates each employee's performance in physical, technical, behavioral, or physiological terms to determine their strengths and weaknesses and find ways in which they can improve their performance (Aladwan et al., 2015; Pahi et al., 2020). Coffie et al. (2018) pointed out those performance appraisal systems cannot be generalized or easily transplanted from one organization to another. They should be specifically designed to match the values and characteristics of an organization and its employees. According to the above discussions, this study developed the following hypothesis: 
H1d: There is a significant relationship between Performance appraisal and Organizational Commitment to employees in the Yemen Islamic banking sector.

\subsection{Tribalism, HRM practices, and OC}

Adra (2016) states that tribal identity hurts industrial productivity. By amplifying the positive characteristics of Tribalism members and denigrating non-Tribalism members, employees "protect, enhance, or achieve a positive social identity" for themselves and their in-group members (Baabbad, 2015). Consequently, they may be less likely to accept, endorse, or interact with non-Tribalism members. Baabbad (2015) reveals that collectivism as a cultural dimension refers to the fact that the people act mainly as members of a lifelong and coherent group. Furthermore, the people have large outspread families, which are used as a safeguard in exchange for unquestioning allegiance (Brandt, 2017). These Tribalism customs reflect the interdependence between members of the tribe. Arab countries like Yemen have a unique societal structure with varying tribes.

- H2: Tribalism has a mediating effect on the relationship between HRM and organizational commitment in the Yemen Islamic banking sector.

\section{Conceptual Framework}

Based on the previous literature, the variables have been selected for the study, which was presented in the framework. Some theories, such as Hofstede's Cultural, social exchange, are used to develop the research model depicted in (see figure 1), demonstrating the relationship between the dependent variable organizational commitment, independent variables HRM practices, and mediating variable Tribalism. In line with Allen et al. (2003), positive perceptions of HRM practices lead to increased OC.

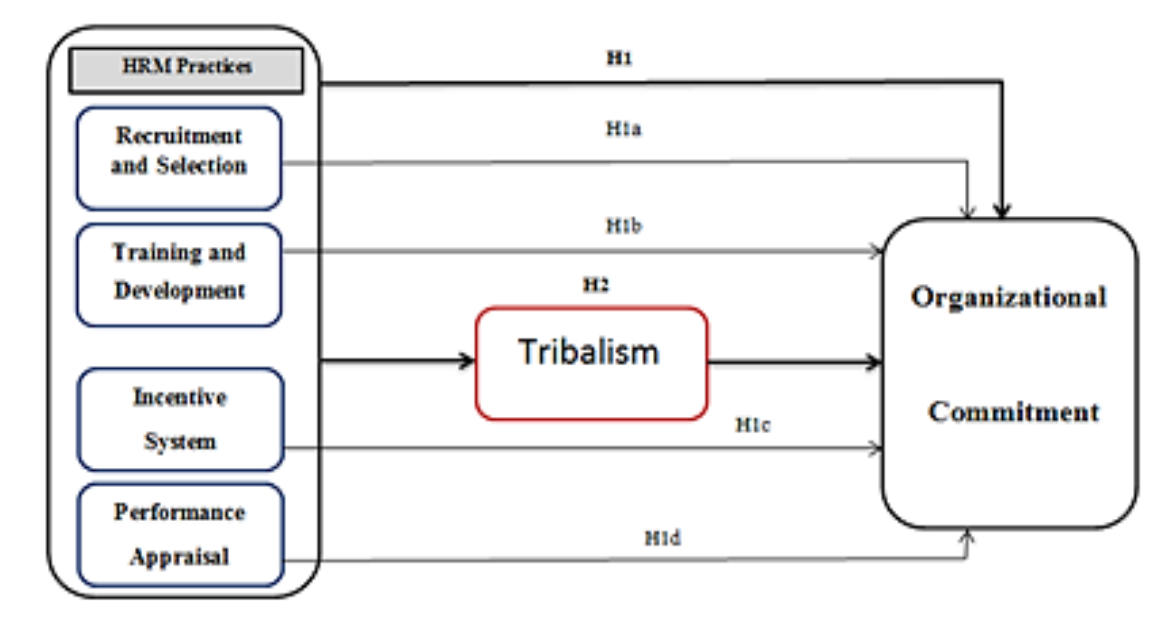

Fig. 1. Conceptual Framework

\section{Methodology}

This study was conducted in Yemen Islamic banks sector. This study is cross-sectional, whereby data is gathered once to answer the study's research questions. Although a longitudinal design is often preferred over cross-sectional because it increases the quality of the data collection and the depth of analysis to test the study hypotheses, it is expensive and timeconsuming. As a result, the cross-sectional design was implemented in this study. This study also uses quantitative approaches. The quantitative design is used in this study to test hypotheses. It is most often associated with a deductive approach, consisting of theory and tests, providing evidence for or against a pre-specified hypothesis. The survey employs questionnaires to obtain personal and social facts, beliefs, and attitudes. This study's unit of analysis is the individual level, whereby a survey distributes in four banks. This study's target population focuses on three regions, which are selected from the north, middle, and south of Yemen, representing the employees in the Islamic bank's sector in Yemen, that are a total population (2261).

A stratified random sampling technique is used. Stratified sampling is a probability sampling method and a form of random sampling in which the population is divided into two or more groups (strata) according to one or more common attributes (Cooper \& Schindler, 2014). Because it has the least bias and offers the most generalization, it intends to guarantee that the sample represents specific subgroups or where every element has an equal chance of being selected as a subject from the population. Stratification produces a smaller error of estimation; the cost per observation in the survey is reduced. This study's target is to have a sample drawn from Islamic banks; thus, stratified random sampling is more suitable for this study. In this regard, the stratified random sampling technique concedes as one of the popular methods 
for collecting data. Since that population of more than (2200) employees are suitable as a sample size, the minimum sample size of 331 is enough for any research as suggested by many scholars (Sekaran \& Bougie, 2016), as shown in Table (1). Data collection questionnaire administered, distributed, and collected personally by the researcher. Data analysis and hypothesis testing through using several statistical tools and methods e employed such as Descriptive Statistic Measures (Data Screening/Cleaning -Factor analysis - Validity- CFA - evaluate construct validity -Reliability- Cronbach Alpha -Correlation), Partial Least Squares Structural Equation Modelling (PLS-SEM).

Table 1. Sampling Frame and Sample Size

\begin{tabular}{llll} 
Regions & Population & Percentage $\%$ & Sample size \\
North & 855 & $38 \%$ & 126 \\
Middle & 715 & $32 \%$ & 106 \\
South & 691 & $30 \%$ & 99 \\
Total & 2261 & $100 \%$ & 331 \\
\hline
\end{tabular}

\section{Measurement}

There are three variables in this study, namely: HRM practices as the independent variables, OC as the dependent variable, and Tribalism as the mediator variable. The questionnaire was used by selecting a five-point Likert scale ranging from: "totally disagree" to "totally agree." The measurements of these three variables were performed according to the recommendations from various sources as follows: Firstly: developed based modified analysis of HRM from the previous HRM studies, measuring four HRM practices in Islamic banks in Yemen, which involve (a) Recruitment and Selection (b) Training and development (c) Incentive system and (d) Performance appraisal. Thus, the measurement of HRM consists of (27) items. Secondly, OC is measured by using three-dimensional models of OC, developed, validated, and revised by Allen \& Meyer (1993). Thus, the measurement of OC consists of 18 items. Thirdly, the analysis of Tribalism consists of 9 items as an appendix (1). The questionnaire items for measurement of Tribalism adapted from Organizational culture measure.

\section{Pilot Study}

The researcher has conducted a pilot test to measure the clarity and reliability of the questionnaires used in the study and test the measures' internal reliability using Cronbach's Alpha reliability coefficients and factor analysis. Also "intended to reveal errors in the design and improper control of extraneous or environmental conditions." Thus, a pilot study was conducted before deciding on the actual instrument to be utilized by using a sample of 30 employees from the Islamic banks' sector in Yemen. The researcher distributed the version of the questionnaire randomly to 30 employees in 4 Islamic banks sector in Yemen to measure the questionnaires' clarity and reliability. After the survey was filled out, the questionnaire's data were clear, understandable, and accessible to all of them. Test of internal reliability (Cronbach's Alpha) of each questionnaire conducted using the Statistical Package of Social Sciences (SPSS), version 25.0. All the measures showed adequate levels of internal reliability.

The results for the pilot study shown in Table (2). Reliability estimates ranged from (0.987 to 0.768) which was considered enough for research purposes. Hence the scales can be regarded as reliable. The pilot test also identified some problems in the questionnaire content, understanding of items, and time took. Some vague sentences were noted and corrected. Thus, amendments were made to the final version. Table (2) shows the values of Alpha for each variable.

Table 2. Reliability Coefficient for Multiple Items in Pilot Study ( $=30)$

\begin{tabular}{lcc}
\multicolumn{1}{c}{ Variable } & N. Of Items & Cronbach's Alpha (a) \\
Recruitment and Selection (RS) & 6 & 0.986 \\
Training and Development (TD) & 7 & 0.985 \\
Incentive System (IS) & 7 & 0.955 \\
Performance Appraisal (PA) & 7 & 0.951 \\
HRM practices & $\mathbf{2 7}$ & $\mathbf{0 . 9 8 7}$ \\
Tribalism (TR) & 9 & 0.960 \\
Affective Commitment (AC) & 6 & 0.768 \\
Continuance Commitment (CC) & 6 & 0.979 \\
Normative Commitment (NC) & 6 & 0.902 \\
Organizational Commitment (OC) & $\mathbf{1 8}$ & $\mathbf{0 . 8 5 6}$ \\
\hline
\end{tabular}




\section{Conclusion}

Organizational commitment has been considered an essential topic that attracts both practitioners and academicians who studied the changes in the behavioral and organizational of business organizations because it helps maintain stability and help the organization achieve high-quality performance. A study suggested that HRM practices are influential factors in increasing organizational commitment; this makes it clear in this study the influence of Tribalism culture as a mediating variable in human-resource management practices on OC in the Yemeni Islamic banks, as it is one of the critical social issues in Yemen, where that Tribalism culture issues play a crucial role in HRM practices, which in turn affects mostly on positive and negative effects to involvement and commitment of the employees, and possibly threaten the independence of the HR practices which assist in finding ways to ensure of motivating employees on organizational commitment. Thus, perform their functions in a motivated, desired, and committed form. Therefore, this study contributes to enrich the present literature in many ways, such as: Investigating the impact of HRM Practices on OC in a developing country, notably Yemen, examining the mediating effect of culture (Tribalism) on the relationship between HRM Practices and OC.

Moreover, this study presents conceptual and pilot studies; the objectives of the theory could be known through Clarify the subject of research and formulate more tightly to study it more deeply in the future and to define the concepts relevant to the issue, and study variables chosen by the researcher for study by identifying the problem of research or formulating it in good form, and the development of hypotheses. As the objectives of the pilot studies can be known, through the clarity and reliability of the questionnaires using Cronbach's Alpha reliability coefficients and factor analysis, because of the transparency and reliability of the research questions, limitations can be identified in the procedures for the application of the search data collection tools, also the practice of applying tests, identifying difficulties and trying to solve them.

The results of the pilot study were positive; the study questions were clear and easy for the pilot sample, as well as all notes for the participants have been codified, and the shortcomings of the following questionnaire avoid, which would be on a larger community sample and more detailed questions.

\section{References}

Adra, N. (2016). Tribal mediation and empowered women: Potential contributions of heritage to national development in Yemen. International Journal of Islamic Architecture, 5(2), 301-337.

Aladwan, K., Bhanugopan, R., \& D'Netto, B. (2015). The effects of human resource management practices on employees' organisational commitment. International Journal of Organizational Analysis.

Allen, D. G., Shore, L. M., \& Griffeth, R. W. (2003). The role of perceived organizational support and supportive human resource practices in the turnover process. Journal of Management, 29(1), 99-118.

Allen, N. J., \& Meyer, J. P. (1993). Organizational commitment: evidence of career stage effects? Journal of Business Research, 26(1), 49-61.

Altarawneh, I. (2009). Training and Development Evaluation in Jordanian Banking Organisations. Research \& Practice in Human Resource Management, 17(1).

Alkadash, T. (2020). Mediating Role between Authentic Leadership, Organizational Commitment on Talents Turnover Intention: in Palestine Higher Education. TEST Engineering \& Management, 83, 5320-5341.

Alkadash, T. M. (2017) Does Global Human Resource Practice Affect Employee Job Satisfaction In Palestinian Firm's? An Evidence-Based Analytical.

AlZgool, M. R. H. (2020). Understanding the Dynamic Nexus between Green Human Resource Management and Environmental Performance: The Moderating Role of Green Leaders' Emotional Intelligence in the Pharmaceutical Sector of Bahrain. Systematic Reviews in Pharmacy, 11(2), 777785 .

Azim, M. T., Fan, L., Uddin, M. A., Jilani, M. M. A. K., \& Begum, S. (2019). Linking transformational leadership with employees' engagement in the creative process. Management Research Review.

Baabbad, M. (2015). The influence of regulatory sanctions and Tribalism on perceived auditor independence: the Yemeni evidence.

Brandt, M. (2017). Tribes and politics in Yemen: A History of the Houthi conflict. Oxford University Press.

Chew, J., \& Chan, C. C. A. (2008). Human resource practices, organizational commitment and intention to stay. International Journal of Manpower.

Coffie, W., Aboagye-Otchere, F., \& Musah, A. (2018). Corporate social responsibility disclosures (CSRD), corporate governance and the degree of multinational activities. Journal of Accounting in Emerging Economies.

Cooper, D. R., \& Schindler, P. S. (2014). Business Research Methods.CThe McGraw-Hill Companies

DeCenzo, D. A., Robbins, S. P., \& Verhulst, S. L. (2016). Fundamentals of human resource management. John Wiley \& Sons

Emam, A. S., Jais, J. B., \& Tabash, M. I. (2019). Training practices and Organizational Commitment in the Yemeni Islamic Banking Sector: The Mediating Role of Tribalism. Journal of Business and Retail Management Research, 13(3).

Eunice, A. E. (2014). The link between human resource management practices and organisational commitment. Indian Journal of Management Science, $4(1), 10$.

Hassan, S., \& Mahmood, B. (2016). Relationship between HRM practices and organizational commitment of employees: An empirical study of textile sector in Pakistan. International Journal of Academic Research in Accounting, Finance and Management Sciences, 6(1), 23-28.

Hsieh, Y.-C., Weng, J., \& Lin, T. (2018). How social enterprises manage their organizational identification: a theoretical framework of identity management approach through attraction, selection, and socialization. The International Journal of Human Resource Management, 29(20), 28802904.

Katou, A. A. (2008). Measuring the impact of HRM on organizational performance. Journal of Industrial Engineering and Management (JIEM), 1(2), $119-142$.

Lamba, S., \& Choudhary, N. (2013). Impact of HRM practices on organizational commitment of employees. International Journal of Advancements in Research \& Technology, 2(4), 407-423.

McGuire, D., Bagher, M., Yap, M., Holmes, M. R., Hannan, C., \& Cukier, W. (2010). The relationship between diversity training, organizational commitment, and career satisfaction. Journal of European Industrial Training.

Pahi, M. H., Ahmed, U., Sheikh, A. Z., Dakhan, S. A., Khuwaja, F. M., \& Ramayah, T. (2020). Leadership and Commitment to Service Quality in Pakistani Hospitals: The Contingent Role of Role Clarity. SAGE Open, 10(4), 2158244020963642.

Palmer, L. (2000). The Impact of Human Resource Management Practices on Employees' Commitment in the Banking Sector in Kingston, Jamaica: to 
25; Pages: 26 to 50; Pages: 51 to 75; Pages: 76 to 100; Pages: 101 to 125; Pages: 126 to 132. ProQuest.

Qiao, K., Luan, X., \& Wang, X. (2008). HRM practices and organizational commitment: a study about IT employees from Chinese private-owned enterprises. 2008 th International Conference on Wireless Communications, Networking and Mobile Computing, 1-6.

Sekaran, U., \& Bougie, R. (2016). Research methods for business: A skill building approach. John Wiley \& Sons.

Steers, R. M., \& Porter, L. W. (1974). The role of task-goal attributes in employee performance. Psychological Bulletin, 81(7), 434.

Wang, C., Hu, R., \& Zhang, T. C. (2020). Corporate social responsibility in international hotel chains and its effects on local employees: Scale development and empirical testing in China. International Journal of Hospitality Management, 90, 102598.

Warsame, A. S. (2015). Human resource management practices and organizational commitment. ISTANBUL AYDIN UNIVERSITY INSTITUTE OF SOCIAL SCIENCES.

Yamao, S., \& Sekiguchi, T. (2015). Employee commitment to corporate globalization: The role of English language proficiency and human resource practices. Journal of World Business, 50(1), 168-179.

Zaitouni, M., Sawalha, N. N., \& El Sharif, A. (2011). The impact of human resource management practices on organizational commitment in the banking sector in Kuwait. International Journal of Business and Management, 6(6), 108.

\section{Appendix A. Dimension Tribalism}

\begin{tabular}{l} 
Items \\
1. In my bank, my tribe identity is an obstacle to confront problems constructively. \\
2. In my bank, my tribe identity is an obstacle to work cooperatively. \\
3. In my bank, my tribe identity is an obstacle to work with resolving disagreements cooperatively. \\
4. In my bank, my tribe identity is an obstacle to work directly and honestly with my workmates. \\
5. In my bank, my tribe identity is an obstacle to getting an atmosphere of trust. \\
6. In my bank, because of my tribe identity, my opinion is not counted. \\
7. In my bank, because of my tribe identity, my ideas are not valued. \\
8. In my bank, because of my tribe identity, I feel like not being part of the family. \\
9. In my bank, because of my tribe identity, I seldom asked to suggest how to make my job better. \\
\hline
\end{tabular}

